\title{
Erratum: Continuous infusion of two doses of remifentanil immediately after laparoscopic-assisted vaginal hysterectomy (Korean J Anesthesiol 2010; 58(6): 537-541)
}

\author{
Jae Jun Lee, Sung Mi Hwang, Jun Sung Lee, Sung Jun Hong, Soo Kyung Lee, and So Young Lim \\ Department of Anesthesiology and Pain Medicine, College of Medicine, Hallym University, Chuncheon, Korea
}

The article by Lee JJ, et al. entitled, "Continuous infusion of two doses of remifentanil immediately after laparoscopicassisted vaginal hysterectomy" (Korean J Anesthesiol 2010; 58(6): 537-541) contained an error in References.

\section{References}

13. Kucukemere F, Kunt N, Kaygusuz K, Kiliccioglu F, Gurelik B, Cetin A. Remifentanil compared with morphine for postoperative patientcontrolled analgesia after major abdominal surgery; a randomized controlled trial. Eur J Anaesthesiol 2005; 22: 378-85.

\section{The correct information is found below:}

\section{References}

13. Choi SH, Koo BN, Nam SH, Lee SJ, Kim KJ, Kil HK, et al. Comparison of remifentanil and fentanyl for postoperative pain control after abdominal hysterectomy. Yonsei Med J 2008; 49: 204-10.

The authors apologize for any inconvenience this mistake may have caused.

\footnotetext{
Corresponding author: Sung Mi Hwang, M.D., Department of Anesthesiology and Pain Medicine, College of Medicine, Hallym University, Chuncheon Sacred Heart Hospital, Gyo-dong, Chuncheon 200-704, Korea. Tel: 82-33-240-5155, Fax: 82-33-252-0941, E-mail: h70sm@hallym.or.kr (C) This is an open-access article distributed under the terms of the Creative Commons Attribution Non-Commercial License (http:// creativecommons.org/licenses/by-nc/3.0/), which permits unrestricted non-commercial use, distribution, and reproduction in any medium, provided the original work is properly cited.
} 